\title{
Asymptomatic Plasmodium falciparum infection is associated with anaemia in pregnancy and can be more cost-effectively detected by rapid diagnostic test than by microscopy in Kinshasa, Democratic Republic of the Congo
}

\author{
Junior R Matangila ${ }^{1,3^{*}}$, Jean Lufuluabo², Axel L Ibalanky ${ }^{1}$, Raquel A Inocêncio da Luz ${ }^{3}$, Pascal Lutumba ${ }^{1}$
} and Jean-Pierre Van Geertruyden ${ }^{3}$

\begin{abstract}
Background: In areas of high malaria transmission, Plasmodium falciparum infection during pregnancy is characterized by malaria-related anaemia, placental malaria and does not always result in clinical symptoms. This situation is associated with poor pregnancy outcomes. The aim of this study was to determine the extent of asymptomatic $P$. falciparum infection, its relation with anaemia as well as the most cost-effective technique for its diagnosis in healthy pregnant women living in Kinshasa, Democratic Republic of the Congo.

Methods: In a cross-sectional study design, information on socio-demographic characteristics and cost data were collected in healthy pregnant women attending antenatal care consultations. Plasmodium falciparum infection was diagnosed using rapid diagnostic test (RDT), microscopy and polymerase chain reaction (PCR). Haemoglobin concentration was also determined.

Results: In total, 332 pregnant women were enrolled. RDT and microscopy data were available for all the blood samples and 166 samples were analysed by PCR. The prevalence of asymptomatic $P$. falciparum infection using microscopy, RDTs and PCR, were respectively $21.6 \%, 27.4 \%$ and $29.5 \%$. Taking PCR as a reference, RDTs had a sensitivity of $81.6 \%$ and a specificity of $94.9 \%$ to diagnose asymptomatic $P$. falciparum infection. The corresponding values for microscopy were $67.3 \%$ and $97.4 \%$. The prevalence of anaemia was $61.1 \%$ and asymptomatic malaria increased five times the odds $(p<0.001)$ of having anaemia. RDTs were more cost-effective compared to microscopy. Incremental cost-effectiveness ratio was US\$ 63.47 per microscopy adequately diagnosed case.
\end{abstract}

Conclusion: These alarming results emphasize the need to actively diagnose and treat asymptomatic malaria infection during all antenatal care visits. Moreover, in DRC, malaria and anaemia control efforts should be strengthened by promoting the use of insecticide-treated nets, intermittent preventive treatment with sulphadoxine-pyrimethamine and iron and folic acid supplements.

Keywords: Asymptomatic P. falciparum infection, Anaemia, Pregnancy, Cost-effectiveness, Democratic Republic of the Congo

\footnotetext{
* Correspondence: matangilaj@yahoo.fr

'Département de Médecine Tropicale, Université de Kinshasa, B.P. 747,

Kinshasa, XI, République Démocratique du Congo

${ }^{3}$ International Health Unit, Department of Epidemiology, University of

Antwerp, Campus DrieEiken, Universiteitsplein 1, Wilrijk 2610, Belgium

Full list of author information is available at the end of the article
} 


\section{Background}

Malaria infection in pregnant women is a major problem in sub-Saharan Africa (SSA) with significant risks for the mother and their offspring. Malaria in pregnancy is characterized by a secondary anaemia and the presence of parasites in the placenta known as placental malaria, leading to low birth weight, source of perinatal morbidity and mortality. In areas of high $P$. falciparum transmission, where a high proportion of the population is semi-immune, most pregnant women with malaria are asymptomatic [1-4].

The sequestration of infected erythrocytes in the intervillous spaces induces a local inflammation and a massive infiltration of immune cells (macrophages, monocytes and lymphocytes) and is often observed and described as 'inflammatory placental malaria' [2,5]. This condition disturbs exchanges between the mother and the foetus and leads to poor pregnancy outcomes, such as abortion, stillbirths, low birth weight and infant mortality [6]. Annually, up to 200,000 infant deaths are attributed to malaria during pregnancy $[7,8]$. Moreover, untreated asymptomatic malaria evolves in a chronic infection characterized by marked dyserythropoietic changes in the red cell precursors and increased erythrophagocytosis. It has been suggested that these changes may be mediated, at least in part, by high levels of tumour necrosis factor (TNF) [9-11]. Maternal anaemia consequently increases the incidence of maternal death during pregnancy or post-partum, and is associated with increased foetal and infant mortality, prematurity and low birth weight across many populations [12]. In malaria-endemic areas, it is estimated that $25 \%$ of pregnant women are infected with malaria parasites, with the greatest risk of infection and morbidity in primiparous adolescents, and those coinfected with HIV [13].

Diagnosis of asymptomatic P. falciparum infection during pregnancy is, therefore, essential to prevent poor pregnancy outcomes, but presents a great challenge. The absence of clinical signs decreases the chances of a clinical diagnosis and a management guided by a decisional algorithm. Moreover, microscopic diagnosis is often challenged by fluctuating and very low parasite densities, due to placental parasite sequestration, the most common form of asymptomatic malaria during pregnancy [14]. Previous studies showed that RDTs detecting P. falciparum histidine-rich protein 2 (HRP2) are more sensitive than microscopy and appear to be reliable predictors of adverse outcomes of malaria in pregnancy [15]. However, more recent studies have brought conflicting results [16]. While RDTs have been extensively evaluated in malaria among the nonpregnant population, there are few published data on the performance and cost-effectiveness of RDT for diagnosing asymptomatic $P$. falciparum infection during pregnancy in malaria-endemic areas.
In the Democratic Republic of the Congo (DRC), previous studies have evaluated the prevalence of malaria and placental infection [17], the practice of intermittent preventive treatment (IPTp) [18] and the use of insecticide-treated net (ITN) [19] in pregnant women. However, there is very little data on asymptomatic $P$. falciparum infection and its contribution to anaemia among pregnant women. The latest studies were conducted in 1988 and 2003 and reported a prevalence of malaria infection among women attending antenatal clinics (ANCs) to be respectively $22 \%$ and $49 \%$ [20,21]. These prevalence estimates in endemic settings were done by microscopy and may have been different if other methods, such as RDT (Rapid Diagnostic Test) and PCR (Polymerase Chain Reaction), had been used [22].

Therefore, this study determined through microscopy, RDTs and PCR the prevalence of asymptomatic $P$. falciparum infection during pregnancy and its relation to anaemia. In addition, their cost and cost-effectiveness to diagnose asymptomatic P. falciparum infection during pregnancy, in semi-rural setting in Kinshasa, were assessed.

\section{Methods}

This study was conducted at the Centre Hospitalier de Kingasani II (CHK), commonly known as Maternité des Soeurs. With twenty to thirty deliveries daily, it is the most frequented Centre in Kinshasa and countrywide. Located in the heart of the semi-rural areas of the south-eastern suburbs of Kinshasa, the maternity provides invaluable health care at an accessible rate.

In a cross-sectional survey, the prevalence of asymptomatic P. falciparum infection was determined in apparently healthy pregnant women, going to the CHK for their first antenatal care (ANC) visit. Data and blood samples were collected prior to any routine administration of intermittent preventive treatment (IPT). Participants were recruited from July $27^{\text {th }}, 2012$ to August $27^{\text {th }}$, 2012. Women not providing written informed consent or presenting fever, muscle aches or other symptoms suggestive for malaria were excluded. Women who received anti-malarial treatment within the past two weeks were also excluded from the study. A structured questionnaire was used to obtain information on age, parity, and gestational age, level of education, previous or current use of anti-malarial drugs and the use of bed nets.

\section{Blood sample collection}

Blood samples were collected from a finger prick for laboratory analysis which included: thick blood smears for microscopy, RDT performance, determination of haemoglobin concentration and molecular analysis. For molecular analysis, blood was collected on a filter paper (Whatmann $3 \mathrm{MM}$ ), dried thoroughly, put in individual zip lock plastic 
bags containing desiccant and stored at room temperature $\left(<25^{\circ} \mathrm{C}\right)$ until completion of the study and then transported to the Tropical Diseases Research Centre (TDRC) in Zambia for molecular analyses.

\section{Laboratory analysis}

Microscopy, RDTs and PCR were used to detect $P$. falciparum infection. Giemsa-stained thick blood smears (TBS) were used for microscopy. Blood slides were examined using light microscopy at 1,000 $\times$ magnification. Hundred microscopic fields were examined in the thick smear before concluding that a blood slide was negative. All slides were read twice by experienced microscopists. If the discrepancy was greater than $15 \%$, a third reader was used to confirm diagnosis. The parasite density per microlitre of blood was computed using the following formula: (Number of trophozoites $\times 6,000$ )/Number of leucocytes. Besides microscopy, rapid diagnostic tests (RDTs) were also performed. In this study the SD Bioline Malaria Ag $\mathrm{Pf}^{\oplus}$ detecting HRP2 was used.

\section{Plasmodium species-specific diagnostic PCR assay}

As microscopy in pregnancy has a lower sensitivity due to placental sequestering of parasites and RDTs have internal validity problems, species specific PCR was conducted on all microscopy negative samples but RDT positive samples. In addition, 166 randomly chosen samples were analysed using nested Plasmodium species diagnostic PCR assay. Molecular analysis was performed at TDRC Ndola, Zambia.

The blood spot samples of $5 \mathrm{~mm}$ diameter size were soaked in $0.5 \%$ saponin in phosphate-buffered saline (PBS), incubated for 10 minutes at room temperature in a $1.5-\mathrm{ml}$ tube, and centrifuged at $14000 \mathrm{rpm}$. The supernatant was discarded and blood spots were washed in $1 \mathrm{ml}$ of PBS. One hundred Fifty microlitres of a $2 \%$ Chelex-100 resin work solution (Bio-Rad Richmond, CA) and $50 \mu \mathrm{l}$ of water ( $\mathrm{pH}$ 9.5) were added to the sample in a1.5-ml tube and incubated at $100^{\circ} \mathrm{C}$ for 10 minutes. After centrifugation at 10,000 $\mathrm{g}$ for $1 \mathrm{~min}$, the supernatant was collected and stored at $-20^{\circ} \mathrm{C}$, prior to the PCR assay.

\section{Polymerase chain reaction investigation}

Nested PCR assay was performed as a two-step procedure. Firstly, amplification of Plasmodium genus specific fragment was carried out as follow: PCR mixture containing buffer, dNTPs, $\mathrm{MgCl} 2$, primers, Taq polymerases and sterile water. All PCR reactions were carried out in a total volume of $20 \mu \mathrm{l}$. One $\mu \mathrm{l}$ of the purified template DNA was used for the first reaction, in which the fragment spanned by rPLU5 (5' CCTGTT GTTGCCTTAAACTTC 3') and rPLU6 (5' TTAAAATTGTT GCAGTTAAAACG 3') was amplified. Secondly, a $1 \mu \mathrm{l}$ aliquot from the product of the first PCR reaction was subsequently used as a template for
Plasmodium falciparum-specific fragment amplification using FAL1 (5' TTAAACTGGTTTGGGAAAACCAAAT ATATT3') and FAL2 (5' ACACAATGAACTCAA TCAT GACTACCCGTC 3') specific primers [23]. Positive and negative controls were always included in the assays. A negative control without DNA template and a positive control with appropriate template (3D7) were always included.

PCR products were detected by running $20 \mu \mathrm{l}$ of DNA product on a $3 \%$ agarose gel, small fragments (Eurogentec ${ }^{\circ}$ ), which was subsequently stained with a $0.5 \mu \mathrm{g} / \mathrm{ml}$ ethidium bromide solution and visualized under ultraviolet transillumination. The specific size of the PCR product (second amplification) was $205 \mathrm{bp}$ for P. falciparum.

\section{Haemoglobin concentration}

Determining the concentration of haemoglobin was performed with a portable $\mathrm{HemoControl}^{\circ}$ device. Anaemia was defined by a haemoglobin concentration $<11 \mathrm{~g} / \mathrm{dL}$. Anaemia was classified as severe anaemia $\mathrm{Hb}<7 \mathrm{~g} / \mathrm{dl}$, moderate anaemia $\mathrm{Hb}: 7-9.9 \mathrm{~g} / \mathrm{dl}$ and mild anaemia $\mathrm{Hb}$ : $10-10.9 \mathrm{~g} / \mathrm{dl}$. [24].

\section{Statistical analysis}

The population of pregnant women in the health zone of Kingasani was estimated at 7,187 [25]. With an expected malaria prevalence of $30 \%$, a desired accuracy set at $5 \%$ and a confidence interval of $95 \%$, the minimum sample size was calculated at 309 pregnant women.

Data was entered and stored in Epi info ${ }^{\mathrm{Dx}} 7$. Descriptive statistics were employed for the analysis of sociodemographic data. Frequencies were used to assess the prevalence of asymptomatic malaria and anaemia in pregnant women. The $\mathrm{x} 2$ test was used to investigate associations between categorical variables. Odds ratios (ORs), 95\% confidence intervals (CIs) were calculated and $\mathrm{p}<0.05$ values were considered to be statistically significant. Multivariate logistic regression models were constructed to identify factors associated with asymptomatic malaria or anaemia during pregnancy. Based on a priori knowledge and a $P$ value less than 0.05 considered as significant, the following variables: Age, sex, parity, marital status, ownership of bed net, presence of lattice on windows, malaria infection and geophagia were included in the model. Backward regression technique was used to construct the model. Statistical analyses were performed using SPSS statistical program, version 17 (SPSS, Chicago, IL, USA).

The sensitivity, specificity, positive predictive value (PPV) and negative predictive value (NPV) of microscopy and RDT (SD Bioline malaria Ag Pf ${ }^{\circ}$ ) were determined with PCR as gold standard, for the 166 samples (50\%) of which PCR results were available. 


\section{Collection of data to estimate the cost of $P$. falciparum infection diagnosis}

Financial data were obtained by conducting interviews with Hospital managers and laboratory staff in Kingasani health Zone. Costs were collected in Congolese Francs (CDF) and converted to US dollars (exchange rate US\$1 = CDF 920, July 2012). The cost for one thick blood smear includes: a glass slide, cotton, lancet, Giemsa and other stains, immersion oil, alcohol and gloves. The personnel cost for the service provided corresponded to the time spent from drawing blood samples, preparing the thick and thin smears, staining, reading and reporting the results. At CHK II as in all public maternities in Kinshasa, RDT kits are donated and the personnel service is free of charge. In the present study, for RDT diagnostic strategy, the effective contact time with those seeking care, which accounted for the personnel cost, and the cost of RDT kit were the main input parameters to figure out the amount of money a pregnant women would pay. The effective contact time was comprised of: drawing blood samples from patients, applying samples onto the test, test reading and reporting of results. The time was recorded on a "time sheet" by laboratory personnel for every RDT and microscopy service provided. Laboratory staff work eight hours from Monday to Friday and 5 hours on Saturday, thus 68 hours (4,080 minutes) weekly. Assuming a month of four weeks; laboratory staff work 272 hours (16,320 minutes) monthly. Staff salary data were provided by the staff manager.

\section{Ethical considerations}

This study was approved by the Ethical Committee board of the University of Kinshasa. Test results of the thick blood smear were revealed to all participants three days after sample collection. All women were given mebendazole, iron and folic acid on a routine basis and were treated with SP regardless of the laboratory test results.

\section{Results}

\section{Socio-demographic characteristics of the} pregnant women

In total, 332 pregnant women from 18 to 39 years old agreed to participate in the study. The median age was 27 years (interquartile range $(\mathrm{IQR})=22-33)$, and $26 \%$ were primigravidae, the median gravidity was $3(\mathrm{IQR}=1-5)$. Eighty one percent of the subjects were married and $66.2 \%$ had not completed secondary school. Thirty-seven percent (37\%) of the pregnant women had started their antenatal care in the third trimester. The mean gestational age in primigravidae at the time of the first prenatal visit was 21.5 weeks $(\mathrm{SD} \pm 4.2)$ vs. 23.6 weeks $(\mathrm{SD} \pm 5.8)$ in multigravida $(\mathrm{p}<0.01)$ (Table 1$)$.
Prevalence of asymptomatic $P$. falciparum infection in pregnant women at the first prenatal care (PNC) visit RDT and microscopy data were available for 332 blood samples and of these, 166 samples were analysed by PCR. The prevalence of asymptomatic $P$. falciparum infection using microscopy, RDTs and PCR, were respectively $21.6 \%$ (95\% CI:17.4-26.6\%), 27.4\% (95\% CI:22.5-32.6\%) and 29.5\% (95\% CI:22.7-37.1\%). Plasmodium malariae was diagnosed in five women by microscopy, but was not confirmed by PCR. The median parasite density was 126/ $\mu$ l (IQR:105162). In bivariate analyses, age, gravidity, marital status and the use of bed nets demonstrated a significant association with asymptomatic malaria. The regression model shows that being younger than 20 years old was an independent risk factor associated with asymptomatic $P$. falciparum infection (AOR 3.2;95\% CI:1.2-8.2, $\mathrm{p}=0.02$ ), while being married (AOR 0.3;95\% CI:0.2-0.8, p=0.01) and spending the night under a bed net (AOR 0.4; $95 \%$ CI:0.2-0.7, p < 0.01) was associated with low prevalence of asymptomatic $P$. falciparum infection (Table 1 ).

\section{Prevalence of anaemia}

The mean haemoglobin concentration was $10.5 \pm 1.4 \mathrm{~g} / \mathrm{dL}$ and the prevalence of anaemia was 61.1\% (95\% CI:55.766.4). Of these anaemic pregnant women, 70 (21.1\%), 132 (39.7\%), 1 (0.3\%), had respectively, mild, moderate and severe anaemia. In multivariate analyses, asymptomatic malaria increased five times the likelihood of having anaemia (AOR 5 95\% CI:2.3-10.1; p 0.001) (Tables 1 and 2).

\section{Possession and use of insecticide-treated nets}

Of all participants, $43.1 \%$ (95\% CI:37.7-48.6\%) possessed a bed net. Of these, $69.8 \%$ stated that their nets were treated with insecticide and $81.8 \%$ reported having slept under the bed net the night before the interview (Table 1).

\section{PCR confirmation of the RDT positive but microscopy negative cases}

Out of 332 samples, 92 were RDT positive and 72 were microscopy positive. All 72 microscopy positive samples were confirmed by RDT. Analysis of the 20 samples that were microscopy negative but RDT positive revealed that $65 \%(13 / 20)$ were positive by PCR (95\% CI: 40.8- 84.6) (Figure 1).

\section{Validity of microscopy and RDT using species specific PCR as golden standard}

PCR was performed on 166 random chosen samples. Using PCR as the gold standard, microscopy and RDTs had a sensitivity of respectively $67.3 \%$ (95\% CI:52.5-80.1) and $81.6 \%$ (95\% CI:68.0-91.2) to diagnose asymptomatic P. falciparum infection. Specificity was $97.4 \%$ (95\% CI:92.7-99.5) and 94.9\% (95\% CI:89.2-98.1) for microscopy 
Table 1 Predictors for asymptomatic $P$. falciparum infection and anaemia in asymptomatic pregnant women in semi-rural suburbs of Kinshasa, 2012

\begin{tabular}{|c|c|c|c|c|c|c|c|c|c|c|c|c|}
\hline \multirow[b]{2}{*}{ Socio-demographic characteristic } & & \multirow[b]{2}{*}{$\mathbf{N}$} & \multicolumn{5}{|c|}{ Asymptomatic $P$. falciparum } & \multicolumn{5}{|c|}{ Anaemia } \\
\hline & & & Positive TBS & OR & $P$ value & AOR $95 \% \mathrm{Cl}$ & $P$ value & Anaemia & OR & $P$ value & AOR & $P$ value \\
\hline \multirow[t]{2}{*}{ Age } & $<20$ & $47(14.2)$ & $24(51.1)$ & 5.2 & $<0.001$ & $3.2(1.2-8.2)$ & $0.02^{*}$ & $34(72.3)$ & 1.8 & 0.09 & $0.9(0.3-2.4)$ & 0.8 \\
\hline & $20-49$ & 285(85.8) & $48(16.9)$ & 1 & & & & 169(59.3) & 1 & & & \\
\hline \multirow[t]{2}{*}{ Gravidity } & Primigravidae & $86(25.9)$ & $27(31.4)$ & 2.0 & 0.01 & $0.8(0.3-1.7)$ & 0.5 & $59(68.6)$ & 1.5 & 0.1 & $1.5(0.8-2.9)$ & 0.2 \\
\hline & Multigravidae & $246(74.1)$ & $45(18.3)$ & 1 & & & & $144(58.5)$ & 1 & & & \\
\hline \multirow[t]{2}{*}{ Gestational age } & $1^{\text {st }}$ et $2^{\text {ème }}$ trimester & $209(63.0)$ & $42(20.1)$ & 0.8 & 0.4 & $0.7(0.4-1.3)$ & 0.3 & $134(61.8)$ & 1.1 & 0.7 & $1.1(0.6-1.8)$ & 0.7 \\
\hline & $3^{\text {rd }}$ trimester & $123(37.0)$ & $30(24.4)$ & 1 & & & & $69(60.0)$ & 1 & & & \\
\hline \multirow[t]{2}{*}{ Marital Status $^{\circ}$} & Married & 259(80.9) & $41(15.8)$ & 0.22 & $<0.001$ & $0.3(0.2-0.8)$ & $0.01^{*}$ & 153(59.1) & 0.7 & 0.2 & $1.3(0.6-2.9)$ & 0.6 \\
\hline & Single & $61(19.1)$ & 28(45.9) & 1 & & & & $41(67.2)$ & 1 & & & \\
\hline \multirow[t]{3}{*}{ Ownership and use of bed net } & Yes and used & $117(35.2)$ & $13(11.1)$ & 0.4 & 0.002 & $0.4(0.2-0.7)$ & $0.005^{*}$ & $72(61.5)$ & 1 & & & \\
\hline & Yes not used & $26(7.8)$ & $10(38.5)$ & 1.8 & 0.2 & $1.9(0.8-4.9)$ & 0.2 & $17(65.4)$ & 1 & 0.8 & $0.9(0.3-2.4)$ & 0.8 \\
\hline & No & 189(56.9) & $49(25.9)$ & 1 & & & & $114(60.3)$ & 1.2 & 0.7 & $0.7(0.5-1.2)$ & 0.2 \\
\hline \multirow[t]{2}{*}{ Presence of lattice on windows } & Yes & $55(16.6)$ & $13(23.6)$ & 1.1 & 0.7 & $1.1(0.5-2.5)$ & 0.7 & $36(65.5)$ & 1.2 & 0.5 & $1.6(0.5-4.4)$ & 0.4 \\
\hline & No & $277(83.4)$ & $59(21.3)$ & 1 & & & & $164(60.3)$ & 1 & & & \\
\hline \multirow[t]{2}{*}{ Malaria } & Yes & $72(21.7)$ & NA & & & & & $60(83.3)$ & 4.1 & $<0.001^{*}$ & $5(2.3-10.1)$ & $<0.001^{*}$ \\
\hline & No & $260(78.3)$ & NA & & & & & 143(55.0) & 1 & & & \\
\hline \multirow[t]{2}{*}{ Geophagia } & Yes & $180(54.2)$ & NA & & & & & 103(57.2) & 0.7 & 0.1 & $0.7(0.5-1.2)$ & 0.2 \\
\hline & No & $152(45.8)$ & NA & & & & & $100(65.8)$ & 1 & & & \\
\hline
\end{tabular}

NA: Not applicable *Significant at $\mathrm{p}<0.05$, OR- odds ratio, AOR- adjusted odds ratio, C.I- confidence interval. ${ }^{\circ} \mathrm{N}=320$. 
Table 2 Prevalence of anaemia in pregnant women in semi-rural suburbs of Kinshasa, $2012(\mathrm{~N}=332)$

\begin{tabular}{lllll}
\hline & & Percentage & $\begin{array}{l}\text { Median (Parasite } \\
\text { density) }\end{array}$ \\
\hline $\begin{array}{l}\text { Haemoglobin } \\
\text { concentration }\end{array}$ & $\begin{array}{l}\text { Severe anaemia } \\
<7 \mathrm{~g} / \mathrm{dl}\end{array}$ & 1 & $0.3 \%$ & 128 (IQR: 128-128) \\
& $\begin{array}{l}\text { Moderate } \\
\text { anaemia } \\
7-9.9 \mathrm{~g} / \mathrm{dl}\end{array}$ & 135 & $40.7 \%$ & 100 (IQR: 78-132) \\
& & & \\
\hline $\begin{array}{l}\text { Slight anaemia } \\
10-10.9 \mathrm{~g} / \mathrm{dl}\end{array}$ & 67 & $20.2 \%$ & 127 (IQR: 103-159) \\
& & & \\
& $\begin{array}{l}\text { Non-anaemic } \\
\geq 11 \mathrm{~g} / \mathrm{dl}\end{array}$ & 129 & $38.9 \%$ & 120 (IQR: 83-135) \\
\hline
\end{tabular}

and RDTs, respectively. RDTs demonstrated a positive predictive value (PPV) of $87.0 \%$ (95\% CI:73.7-95.1\%) and a negative predictive value (NPV) of $92.5 \%(95 \%$ CI:86.2-96.5\%). The corresponding values for microscopy were $91.7 \%$ (95\% CI:77.5-98.2\%) and $87.7 \%(95 \%$ CI:80.8-92.8\%). Microscopy combined to RDT demonstrated a sensitivity of $81.6 \%$ (95\% CI:68.0-91.2), a specificity of $94.9 \%$ (95\% CI:89.2-98.1), a PPV of $87.0 \%$ (95\% CI:73.7-95.1\%) and NPV) of 92.5\% (95\% CI:86.2-96.5\%). The differences were not significant for any comparison (Table 3).

\section{Cost-effectiveness of RDT and microscopy}

On the basis of the 166 samples for which PCR results were available, malaria RDT was the most effective with the number of cases correctly diagnosed being 40 (90.9\%) compared to $33(88.6 \%)$ for microscopy (Table 4$)$. The corresponding proportion of patients correctly diagnosed was $90.9 \%$ and $88.6 \%$, respectively. Routine use of RDT would result into an additional $2.3 \%$ of patients correctly diagnosed in comparison to microscopy. Thus, incremental cost-effectiveness ratio was US\$ 63.47 per adequately diagnosed case for microscopy when compared to RDT strategy (Table 5).

\section{Discussion}

In the most frequented maternity in Kinshasa, located in the heart of the semi-rural areas Kinshasa, the prevalence of asymptomatic malaria at the first antenatal visit was $27 \%$ and $21 \%$, using respectively RDT and microscopy. PCR showed that almost one third and one fifth were missed by microscopy and RDT respectively. Microscopy results (21\%) were similar to the $22 \%$ value reported in 1988 [20].

These values are paradoxically lower than the $42 \%$ found in Lubumbashi, an area of low malaria transmission [21]. Asymptomatic infection is a characteristic in areas of high malaria transmission; therefore, one would expect a higher prevalence in Kinshasa. It can be argued that the prevalence of asymptomatic $P$. falciparum infection may have been somewhat lower, because the study was carried out during the dry season, period subjected to a mild/low malaria transmission. Therefore, another survey during the rainy season may be informative.

Parasite density was also found to be very low in all infected pregnant women. P. falciparum-infected but asymptomatic individuals tend to have low and submicroscopic parasite densities [26,27]. Moreover, during pregnancy placental sequestration of parasitized red blood cells may lead to the absence or low grade of peripheral parasitaemia [28].

Other studies also found a protective effect of bed nets against malaria in pregnancy [29]. Other studies have shown that younger women may be more susceptible than older women to malaria because they are still in the process of acquiring natural immunity to pregnancy related malaria [28]. Single women were more likely to have asymptomatic P. falciparum infection compared to married women. In addition, owning a mosquito net was associated with being married, as previously reported by Pettifor et al. in 2008 [19]. This indicates that marriage or living with a partner, may offer women an ideal setting to promote maternal health. Gravidity did not show any association with asymptomatic P. falciparum infection. This indicates that malaria endemicity may be lower than expected impairing the development of immunity against pregnancy-related malaria

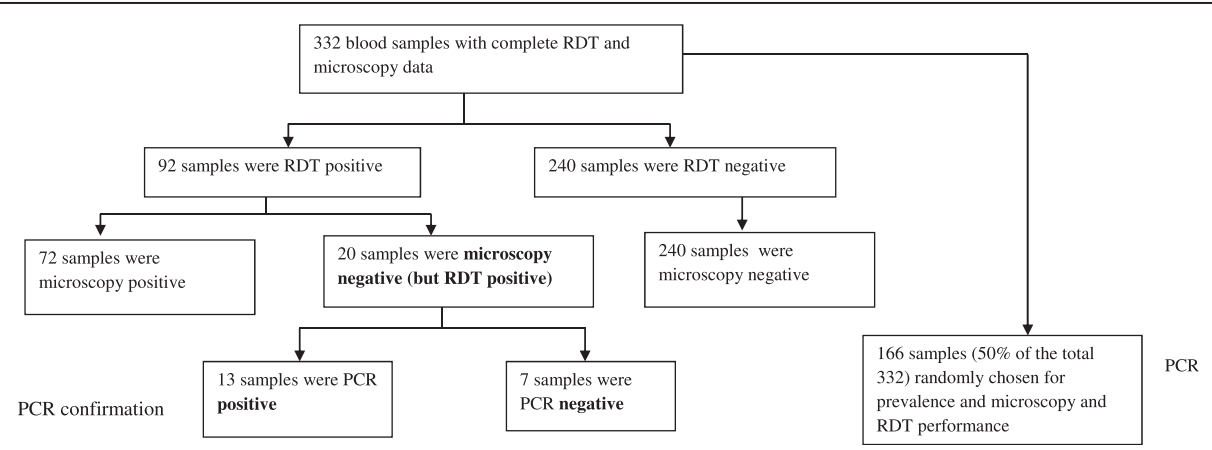

Figure 1 Flow diagram for malaria diagnosis and subsequent PCR analysis in semi-rural suburbs of Kinshasa, 2012. 
Table 3 Comparison of RDT and microscopy performance using PCR as golden standard in semi-rural suburbs of Kinshasa, $2012(\mathrm{~N}=166)$

\begin{tabular}{|c|c|c|c|c|c|c|c|c|}
\hline & & \multicolumn{3}{|c|}{ PCR results } & \multicolumn{4}{|c|}{ Performances } \\
\hline & & Positive & Negative & Total & Sensitivity & Specificity & PPV & NPV \\
\hline \multirow[t]{2}{*}{ Microscopy } & + & 33 & 3 & 36 & $67.3 \%(52.5-80.1)$ & $97.4 \%(92.7-99.5)$ & $91.7 \%(77.5-98.2)$ & $87.7 \%(80.8-92.8)$ \\
\hline & - & 16 & 114 & 130 & & & & \\
\hline \multirow[t]{2}{*}{ RDT } & + & 40 & 6 & 46 & $81.6 \%(68.0-91.2)$ & $94.9 \%(89.2-98.1)$ & $87.0 \%(73.7-95.1)$ & $92.5 \%(86.2-96.5)$ \\
\hline & - & 9 & 111 & 120 & & & & \\
\hline \multirow[t]{2}{*}{ Microscopy and RDT } & + & 40 & 6 & 46 & $81.6 \%(68.0-91.2)$ & $94.9 \%(89.2-98.1)$ & $87.0 \%(73.7-95.1)$ & $92.5 \%(86.2-96.5)$ \\
\hline & - & 9 & 111 & 120 & & & & \\
\hline
\end{tabular}

during successive pregnancies. Similar observations were made in other low malaria-endemic areas [30-33], stressing the need for further studies to assess the endemicity in the DRC. An individual predictor impairing acquisition of immunity is HIV infection [34]. It is, however, very unlikely that this would have affected the present results, as HIV prevalence in ANC in Kinshasa is estimated at 3.9\% [35].

Pregnant women were coming for their first antenatal visit at the time of enrolment, thus prior to any administration of IPTp with SP. However P. falciparum infection in early pregnancy has been associated with adverse outcomes such as low birth weight LBW [33]. The use of bed nets would, therefore, be a suitable option to protect pregnant women during this period. Almost half of the surveyed women $43 \%$ declared to own a bed net. These results are higher than the $26 \%, 33 \%$ and $7 \%$ previously reported by UNDP in 2009 [35], Pettifor et al. in 2008 [19] and the Programme National de Lutte contre le Paludisme (PNLP) in 2007 [36]. However, only 35\% of all pregnant women slept under a bed net, which may suggest a slight awareness of malaria during pregnancy in this specific group [19].

High prevalence of anaemia was observed and strongly correlated with asymptomatic $P$. falciparum infection. This prevalence is similar to those reported in Kisangani in 2000 (65\%) and Lubumbashi (in average 65\%) in 2003

Table 4 Comparison of effectiveness of the two diagnostic strategies $(N=166)$

\begin{tabular}{lll}
\hline Tests results & \multicolumn{2}{c}{ Diagnostic strategy } \\
\cline { 2 - 3 } & RDT & Microscopy \\
\hline True positive & 40 & 33 \\
False positive & 6 & 3 \\
True negative & 111 & 114 \\
False negative & 9 & 16 \\
Total sample analysed & 166 & 166 \\
Number correctly diagnosed & 151 & 147 \\
Proportion correctly diagnosed & 90.9 & 88.6 \\
\hline
\end{tabular}

[37,21]. However, Kinshasa, Kisangani and Lubumbashi belong to three different epidemiological malaria transmission patterns. These findings and the fact that a high proportion of non-malaria infected women were anaemic suggest the presence of other risk factors for anaemia in pregnant women, although the contribution of malaria seems to be significant. The aim of the study was not to assess the risk factors for anaemia in pregnant women; a dedicated study would be more appropriate to disclose this useful information. There was no significant difference in the density of parasitaemia in those with mild, moderate and severe anaemia (Table 2). A similar observation was also reported from Nigeria in 2009 [38]. A limitation of this study was that HIV infection, which is also known to cause anaemia [39], was not documented. Considering HIV when constructing the regression model could have provided more accurate information on the contribution of asymptomatic malaria.

In the present study, no significant difference was found between microscopy and RDT using PCR as the gold standard. This observation was also made elsewhere $[16,40]$. Combination results of RDTs and microscopy did not improve the sensitivity, specificity, PPV as well as NPV to diagnose asymptomatic $P$. falciparum infection. In addition, all the RDT positive but microscopy negative samples were analysed by PCR and it showed that $65 \%$ were in fact submicroscopic infections. The PCR negative samples could be either explained by the persistence of HRP-2 circulation in the blood more than two weeks even after successful clearance of infected erythrocytes in the bloodstream or by the sequestration of the parasites in the placenta while HRP-2

Table 5 Results of the cost-effectiveness analysis of the microscopy compared to RDT , Kingasani health zone, Kinshasa, 2013

\begin{tabular}{llllll}
\hline $\begin{array}{l}\text { Diagnostic } \\
\text { strategy }\end{array}$ & $\begin{array}{l}\text { Cost } \\
\text { (US\$) }\end{array}$ & $\begin{array}{l}\text { Additional } \\
\text { cost (US\$) }\end{array}$ & Effectiveness & $\begin{array}{l}\text { Additional } \\
\text { effectiveness }\end{array}$ & $\begin{array}{l}\text { ICER } \\
\text { (US\$) }\end{array}$ \\
\hline Microscopy & 2.62 & 1.46 & 0.886 & & 63.47 \\
RDT & 1.16 & & 0.909 & 0.023 & \\
\hline
\end{tabular}

ICER: Incremental Cost-effectiveness Ratio. 
Table 6 Cost components and unit costs considered for monthly asymptomatic $P$. falciparum diagnosis, at CHK II, in Kingasani Health Zone, Kinshasa in 2013

\begin{tabular}{|c|c|c|c|}
\hline Items & Unit cost (US\$) & Microscopy strategy (US\$) $(n=332)$ & RDT strategy (US\$) $(n=332)$ \\
\hline \multicolumn{4}{|l|}{ Exams and supplies } \\
\hline Thick blood smear ${ }^{a}$ & 0.72 & 239.04 & - \\
\hline SD Bioline Malaria Antigen Pf ${ }^{\oplus}$ - one test & 0.79 & - & 262.28 \\
\hline \multicolumn{4}{|l|}{ Salary } \\
\hline Laboratory technician salary & 304.34 (monthly) & 588.18 & 123.82 \\
\hline \multicolumn{4}{|l|}{ Equipment } \\
\hline Microscope- one unit - value & 520.82 ( annual) & 43.4 (monthly) & - \\
\hline \multicolumn{4}{|l|}{ Training* } \\
\hline Microscopy - one annual course & - & - & - \\
\hline RDT-one annual course & - & - & - \\
\hline Total & & 870.62 & 386.1 \\
\hline
\end{tabular}

${ }^{a}$ Corresponds to the individual cost of an examination, which includes a glass slide, Giemsa and other stains (all components of stains), oil immersion, lancet, cotton, alcohol and gloves.

*Training costs were not available.

circulate [41]. PCR showed that almost one third and one fifth were missed by microscopy and RDT respectively. These finding highlight the necessity of strengthening IPTp in pregnancy.

This study demonstrated that RDT technique was more cost-effective than microscopy. This finding is supported by others studies carried out in other settings [42,43]. In malaria microscopy, the major cost input was the personnel salary and laboratory equipment. The major parameter that determined the cost of RDT-based strategy was cost of the test. The study did not consider the capital costs of setting up the infrastructure for microscopy diagnosis, which is known to be costly, as well as personnel training from which data were not available (Table 6). If considered, microscopy costs would be higher. Studies have shown that preventive efforts (IPT with SP and insecticide-treated bed net) still leave a large proportion of women with peripheral parasitaemia which is associated with anaemia and impaired delivery outcomes [44]. This highlights the necessity of assessing other strategies such as prompt screening and treatment of women when they present to antenatal care. Therefore, RDT use may be the best available diagnostic alternative for asymptomatic malaria screening in remote or semi-rural endemic areas where infrastructure for microscopy diagnosis is not in place, or where high accuracy of microscopy cannot be assured like in Kinshasa [45].

\section{Conclusion}

This study reports a high prevalence of anaemia among pregnant women in the health zone of Kingasani, Kinshasa and anaemia is strongly correlated to asymptomatic P. falciparum infection. These results are quite alarming and emphasize the need to actively diagnose and treat asymptomatic malaria infection using appropriate techniques during ANC visits in areas of high malaria transmission, regardless of IPTp. On the other hand, though the use of ITNs in DRC is slightly increasing, the promotion of ITN use should be further encouraged. The present study suggests that RDTs may replace blood smears screening of asymptomatic P. falciparum infection in pregnancy in some malaria-endemic settings by virtue of their easeto-use, ability to detect sub-microscopic infection and cost-effectiveness compared with microscopy.

\begin{abstract}
Abbreviations
AOR: Adjusted Odds-ratio; Cl: Confidence Interval; DRC: Democratic Republic of the Congo; IQR: Inter Quartile Range; OR: Odds-ratio; PCR: Polymerase Chain Reaction; PNLP: Programme National de Lutte contre le Paludisme;

PRDT: Rapid Diagnostic Test; SSA: Sub-Saharan Africa; TBS: Thick Blood Smear.
\end{abstract}

\section{Competing interests}

The authors declare that they have no competing interest.

\section{Author's contributions}

JMR participated in the conception and design of the study protocol, conducted the study, draft the manuscript and participated in molecular analysis. $\mathrm{Al}$ and $\mathrm{L}$ participated in the design of the study protocol and conducted the study. RIL, PL, JPV reviewed the manuscript and provided critical inputs. All authors read and approved the final manuscript.

\section{Acknowledgements}

The authors thank all pregnant women who participated in this study and the staff of Centre Hospitalier de Kingasani II (Centre des Soeurs). We also thank Rose Tujibikila, Bruno Nsilulu, and Celestin Atero for assisting in sample collection and analysis. Eric Njunju is thanked for his technical assistance in the setting up of the PCR assays. The team thanks David Mwakazanga for assisting in statistical analysis and Professor Paul Gwakisa for participating in the revision of the manuscript. This study was sponsored by Southern African Centre of Infectious Diseases (SACIDS) and VLIR UOS project (ZRDC2012 70447).

\section{Author details}

'Département de Médecine Tropicale, Université de Kinshasa, B.P. 747, Kinshasa, XI, République Démocratique du Congo. ${ }^{2}$ Institut Superieur de Techniques Médicales, Kinshasa RDC, Kinshasa, République Démocratique du Congo. ${ }^{3}$ International Health Unit, Department of Epidemiology, University of Antwerp, Campus DrieEiken, Universiteitsplein 1, Wilrijk 2610, Belgium.

Received: 24 December 2013 Accepted: 28 March 2014

Published: 2 April 2014 


\section{References}

1. Steketee RW, Wirima JJ, Campbell CC: Developing effective strategies for malaria prevention programs for pregnant African women. Am J Trop Med Hyg 1996, 55(Suppl 1):95-100.

2. Nosten F, Rogerson SJ, Beeson JG, McGready R, Mutabingwa TK, Brabin B: Malaria in pregnancy and the endemicity spectrum: what can we learn? Trends Parasitol 2004, 20:425-432.

3. Sullivan AD, Nyirenda T, Cullinan T, Taylor T, Harlow SD, James SA, Meshnick SR: Malaria infection during pregnancy: intrauterine growth retardation and preterm delivery in Malawi. J Infect Dis 1999, 179:1580-1583.

4. Verhoeff FH, Brabin BJ, Chimsuku L, Kazembe P, Broadhead RL: Malaria in pregnancy and its consequences for the infant in rural Malawi. Ann Trop Med Parasitol 1999, 93(Suppl 1):S25-S33.

5. Ordi J, Menendez C, Ismail MR, Ventura PJ, Palacin A, Kahigwa E, Ferrer B, Cardesa A, Alonso PL: Placental malaria is associated with cell-mediated inflammatory responses with selective absence of natural killer cells. J Infect Dis 2001, 183:1100-1107.

6. Menendez C, Ordi J, Ismail MR, Ventura PJ, Aponte JJ, Kahigwa E, Font F, Alonso PL: The impact of placental malaria on gestational age and birth weight. J Infect Dis 2000, 181:1740-1745.

7. Ismail MR, Ordi J, Menendez C, Ventura PJ, Aponte JJ, Kahigwa E, Hirt R, Cardesa A, Alonso PL: Placental pathology in malaria: a histological, immunohistochemical, and quantitative study. Hum Pathol 2000, 31:85-93.

8. van Geertruyden JP, Thomas F, Erhart A, D'Alessandro U: The contribution of malaria in pregnancy to perinatal mortality. Am J Trop Med Hyg 2004, 71(Suppl 2):35-40.

9. Steketee RW, Nahlen BL, Parise ME, Menendez C: The burden of malaria in pregnancy in malaria-endemic areas. Am J Trop Med Hyg 2001 64(Suppl1-2):28-35.

10. Faquin WC, Schneider TJ, Goldberg MA: Effect of inflammatory cytokines on hypoxia-induced erythropoietin production. Blood 1992, 79:1987-1994.

11. Jelkmann W, Pagel H, Wolff M, Fandrey J: Monokines inhibiting erythropoietin production in human hepatoma cultures and in isolated perfused rat kidneys. Life Sci 1992, 50:301-308.

12. Leopardi O, Naughten W, Salvia L, Colecchia M, Matteelli A, Zucchi A, Shein A Muchi JA, Carosi G, Ghione M: Malaric placentas. A quantitative study and clinico-pathological correlations. Pathol Res Pract 1996, 192:892-898.

13. Schantz-Dunn J, Nour NM: Malaria and pregnancy: a global health perspective. Rev Obstet Gynecol 2009, 2:186-192.

14. Brabin BJ, Romagosa C, Abdelgalil S, Menendez C, Verhoeff FH, McGready R, Fletcher KA, Owens S, D'Alessandro U, Nosten F, Fischer PR, Ordi J: The sick placenta-the role of malaria. Placenta 2004, 25:359-378.

15. Minja DT, Schmiegelow C, Oesterholt M, Magistrado PA, Bostrom S, John D, Pehrson C, ndersen D, Deloron P, Salanti A, Lemnge M, Luty AJ, Alifrangis M, Theander T, Lusingu JP: Reliability of rapid diagnostic tests in diagnosing pregnancy-associated malaria in north-eastern Tanzania. Malar J 2012, $11: 211$.

16. Kyabayinze DJ, Tibenderana JK, Nassali M, Tumwine LK, Riches C, Montague M, Counihan H, Hamade P, van Geertruyden JP, Meek S: Placental Plasmodium falciparum malaria infection: operational accuracy of HRP2 rapid diagnostic tests in a malaria endemic setting. Malar J 2011, 10:306.

17. Lukuka KA, Fumie OS, Mulumbu MR, Lokombe BJ, Muyembe TJ: [Malaria prevalence at delivery in four maternity hospitals of Kinshasa City, Democratic Republic of Congo]. (in French). Bull Soc Pathol Exot 2006, 99:200-201

18. Likwela JL, D'Alessandro U, Lokwa BL, Meuris S, Dramaix MW: Sulfadoxinepyrimethamine resistance and intermittent preventive treatment during pregnancy: a retrospective analysis of birth weight data in the Democratic Republic of Congo (DRC). Trop Med Int Health 2012, 17:322-329.

19. Pettifor A, Taylor E, Nku D, Duvall S, Tabala M, Meshnick S, Behets F: Bed net ownership, use and perceptions among women seeking antenatal care in Kinshasa, Democratic Republic of the Congo (DRC): opportunities for improved maternal and child health. BMC Public Health 2008, 8:331

20. Mbanzulu PN, Leng JJ, Kaba S, Mputu L, Ngimbi NP, Makengo N, Ngbege: [Malaria and pregnancy. Epidemiological situation in Kinshasa (Zaire)] (in French). Rev Fr Gynecol Obstet 1988, 83:99-103.

21. Kalenga MK, Nyembo MK, Nshimba M, Foidart JM: [Anemia associated with malaria and intestinal helminthiasis in Lubumbashi](in French). Sante Publ 2003, 15:413-421.

22. Rantala AM, Taylor SM, Trottman PA, Luntamo M, Mbewe B, Maleta K, Kulmala T, Ashorn P, Meshnick SR: Comparison of real-time PCR and microscopy for malaria parasite detection in Malawian pregnant women. Malar J 2010, 9:269.

23. Snounou G, Viriyakosol S, Zhu XP, Jarra W, Pinheiro L, do Rosario VE, Thaithong S, Brown KN: High sensitivity of detection of human malaria parasites by the use of nested polymerase chain reaction. Mol Biochem Parasitol 1993, 61:315-320.

24. WHO: Iron deficiency anaemia assessment, prevention and control: a guide for programme managers. Geneva, Switzerland: World Health Organization; 2001.

25. Ministère de la Santé: Présentation de la Zone de Santé de Kingasani. ; 2008.

26. Trape JF, Peelman P, Morault-Peelman B: Criteria for diagnosing clinical malaria among a semi-immune population exposed to intense and perennial transmission. Trans R Soc Trop Med Hyg 1985, 79:435-442.

27. Roucher C, Rogier C, Dieye-Ba F, Sokhna C, Tall A, Trape JF: Changing malaria epidemiology and diagnostic criteria for Plasmodium falciparum clinical malaria. PLoS One 2012, 7:e46188.

28. Brabin BJ: An analysis of malaria in pregnancy in Africa. Bull World Health Organ 1983, 61:1005-10016.

29. Mathanga DP, Campbell CH, Taylor TE, Barlow R, Wilson ML: Socially marketed insecticide-treated nets effectively reduce Plasmodium infection and anaemia among children in urban Malawi. Trop Med Int Health 2006, 11:1367-1374.

30. Agan T, Ekabua J, Udoh A, Ekanem E, Efiok E, Mgbekem M: Prevalence of anemia in women with asymptomatic malaria parasitemia at first antenatal care visit at the University of Calabar Teaching Hospital, Calabar, Nigeria. Int J Womens Health 2010, 2:229-233.

31. Anchang-Kimbi JK, Achidi EA, Nkegoum B, Sverremark-Ekstrom E, Troye-Blomberg M: Diagnostic comparison of malaria infection in peripheral blood, placental blood and placental biopsies in Cameroonian parturient women. Malar J 2009, 8:126.

32. Douamba Z, Bisseye C, Djigma FW, Compaore TR, Bazie VJ, Pietra V, Nikiema JB, Simpore J: Asymptomatic malaria correlates with anaemia in pregnant women at Ouagadougou, Burkina Faso. J Biomed Biotechnol 2012, 2012:198317

33. Valea I, Tinto $H$, Drabo MK, Huybregts $L$, Sorgho $H$, Ouedraogo JB, Guiguemde RT, van Geertruyden JP, Kolsteren P, D'Alessandro U: An analysis of timing and frequency of malaria infection during pregnancy in relation to the risk of low birth weight, anaemia and perinatal mortality in Burkina Faso. Malar J 2012, 11:71

34. Mount AM, Mwapasa V, Elliott SR, Beeson JG, Tadesse E, Lema VM, Molyneux ME, Meshnick SR, Rogerson SJ: Impairment of humoral immunity to Plasmodium falciparum malaria in pregnancy by HIV infection. Lancet 2004, 363:1860-1867.

35. UNDP-DRC: Kinshasa, profile summary: Poverty and living conditions of households. ; 2009.

36. President's Malaria Initiative: Malaria Operational Plan Fiscal Year 2012. Democratic Republic of Congo; 2011. http://www.pmi.gov/countries/mops/ fy12/drc_mop_fy12.pdf.

37. Kanku T, Labama $L$, Wembodinga U: Anémie de la femme enceinte à Kisangani : Prévalence et risque liés à quelques indications de risque. Congo Med 2000, 13:915-920

38. Nwagha UI, Ugwu VO, Nwagha TU, Anyaehie BU: Asymptomatic Plasmodium parasitaemia in pregnant Nigerian women: almost a decade after Roll Back Malaria. Trans R Soc Trop Med Hyg 2009, 103:16-20.

39. Nkhoma ET, Kalilani-Phiri L, Mwapasa V, Rogerson SJ, Meshnick SR: Effect of HIV infection and Plasmodium falciparum parasitemia on pregnancy outcomes in Malawi. Am J Trop Med Hyg 2012, 87:29-34.

40. Dhorda M, Piola P, Nyehangane D, Tumwebaze B, Nalusaji A, Nabasumba C, Turyakira E, McGready R, Ashley E, Guerin PJ, Snounou G: Performance of a histidine-rich protein 2 rapid diagnostic test, Paracheck $P f(R)$, for detection of malaria infections in Ugandan pregnant women. Am J Trop Med Hyg 2012, 86:93-95.

41. Humar A, Ohrt C, Harrington MA, Pillai D, Kain KC: Parasight F test compared with the polymerase chain reaction and microscopy for the diagnosis of Plasmodium falciparum malaria in travelers. Am J Trop Med Hyg 1997, 56:44-48.

42. Lubell Y, Reyburn H, Mbakilwa H, Mwangi R, Chonya K, Whitty CJ, Mills A: The cost-effectiveness of parasitologic diagnosis for malaria-suspected patients in an era of combination therapy. Am J Trop Med Hyg 2007, 77(Suppl 6):128-132

43. Uzochukwu BS, Obikeze EN, Onwujekwe OE, Onoka CA, Griffiths UK: Cost-effectiveness analysis of rapid diagnostic test, microscopy and 
syndromic approach in the diagnosis of malaria in Nigeria: implications for scaling-up deployment of ACT. Malar J 2009, 8:265.

44. De Beaudrap P, Turyakira E, White L, Nabasumba C, Tumwebaze B, Muehlenbachs A, Guérin PJ, Boum Y, McGready R, Piola P: Impact of malaria during pregnancy on pregnancy outcomes in a Ugandan prospective cohort with intensive malaria screening and prompt treatment. Malar J 2013, 12:139.

45. Muhindo HM, llombe G, Meya R, Mitashi PM, Kutekemeni A, Gasigwa D, Lutumba P, van Geertruyden JP: Accuracy of malaria rapid diagnosis test Optimal-IT((R)) in Kinshasa, the Democratic Republic of Congo. Malar J 2012, 11:224.

doi:10.1186/1475-2875-13-132

Cite this article as: Matangila et al: Asymptomatic Plasmodium

falciparum infection is associated with anaemia in pregnancy and can

be more cost-effectively detected by rapid diagnostic test than by microscopy in Kinshasa, Democratic Republic of the Congo. Malaria Journal 2014 13:132.

\section{Submit your next manuscript to BioMed Central and take full advantage of:}

- Convenient online submission

- Thorough peer review

- No space constraints or color figure charges

- Immediate publication on acceptance

- Inclusion in PubMed, CAS, Scopus and Google Scholar

- Research which is freely available for redistribution 